\title{
Estudos Sobre o Desenvolvimento Profissional de Professores
}

\author{
Studies on Professional Development of Teachers
}

\author{
Ana Paula Krein Müller*a; Marli Teresinha Quartierib \\ ${ }^{a}$ Universidade do Vale do Taquari, Programa de Pós-Graduação Stricto Sensu em Ensino. RS, Brasil. \\ buniversidade do Vale do Taquari, Programa de Pós-Graduação Stricto em Educação. RS, Brasil. \\ *E-mail: anapmuller@universo.univates.br
}

\begin{abstract}
Resumo
Com o intuito de identificar aproximações com a pesquisa intitulada que está sendo desenvolvida por uma aluna no Doutorado em Ensino, foi realizado um levantamento bibliográfico para conhecer que tipos de estudos estão sendo efetivados com temas relacionados a esta investigação. Com o objetivo realizar uma revisão sistemática em pesquisas que descrevem intervenções com o foco na "formação de professores", "desenvolvimento profissional", de modo a identificar como essa associação tem sido tratada na literatura Realizou-se uma busca nas revistas classificadas com A1 no Portal de periódicos da Capes no período de 2013 a 2018, selecionando os títulos que se aproximavam com os temas discutidos nesta pesquisa: "formação de professores" e "desenvolvimento profissional". Com a análise dos artigos, percebeu-se a necessidade de pesquisas com período maior de formação, buscando formar um professor reflexivo, preocupado em aprimorar sua prática pedagógica, a importância da participação do grupo de professores, a troca e compartilhamento de ideias e atividades, além de alguns apontamentos como em relação a durante dos momentos de formação que podem ser importantes para a constituição de uma formação continuada que busca o desenvolvimento dos professores participantes.
\end{abstract}

Palavras-chave: Desenvolvimento Profissional. Formação de Professores. Prática Pedagógica. Estudo Bibliográfico.

\begin{abstract}
In order to identify similarities with the research entitled that is being developed by a student in the Doctorate in Teaching, a bibliographic survey was carried out to find out what types of studies are being carried out with themes related to this investigation. In order to carry out a systematic review of research that describes interventions with a focus on "teacher training", "professional development", in order to identify how this association has been treated in the literature. A search was made in journals classified with A1 in the Capes journals portal from 2013 to 2018, selecting the titles that approached the topics discussed in this research: "teacher training" and "professional development". With the analysis of the articles, there was a need for research with a longer period of training, seeking to train a reflective teacher, concerned with improving his pedagogical practice, the importance of the participation of the group of teachers, the exchange and sharing of ideas and activities, in addition to some notes such as in relation to during the training moments that may be important for the constitution of a continuing education that seeks the development of the participating teachers.
\end{abstract}

Keywords: Professional Development. Teacher Training. Pedagogical Practice. Bibliographic Study.

\section{Introdução}

A formação de um professor não se conclui com a formação inicial deste profissional. Na maioria das vezes, a aprendizagem e a prática docente se aprimoraram nas situações diárias que exigem do profissional um desenvolvimento amplo, não apenas de conhecimentos, mas de atitudes, valores e também de trabalho colaborativo. Nesse sentido, espera-se que os professores tenham uma prática investigadora e reflexiva e que estejam abertos às mudanças. Sendo assim, é importante considerar o desenvolvimento profissional na formação do professor, buscando aproximação com a prática reflexiva.

O presente estudo teve como objetivo realizar uma revisão sistemática em pesquisas que descrevem intervenções com o foco na "formação de professores", "desenvolvimento profissional", de modo a identificar como essa associação tem sido tratada na literatura. De forma mais específica, em relação a estas pesquisas, os objetivos foram: identificar as metodologias adotadas nos cursos de formação continuada, dificuldades encontradas em ações que buscam o desenvolvimento profissional dos professores, e quais os principais enfoques teóricos e metodológicos adotados nessas investigações. Assim, foi efetivada busca por artigos em revistas Qualis A1 do portal de periódicos da Capes.

O estudo realizado justifica-se como a necessidade de coletarinformações para organização de momentos de formação continuada de professores que busca o desenvolvimento profissional. Este estudo é parte de uma pesquisa de doutorado" intitulada "Formação continuada de professores 
dos anos iniciais em contexto colaborativo: possibilidades para o desenvolvimento profissional e integração de recursos tecnológicos e atividades experimentais" que tem como objetivo analisar como a formação continuada de professores dos Anos Iniciais em contextos colaborativos, promove o desenvolvimento profissional desses docentes.

Cabe destacar que o levantamento foi direcionado aos trabalhos na área de ciências, matemática, recursos tecnológicos e atividades experimentais. Entretanto, neste artigo o foco será nos trabalhos envolvendo desenvolvimento profissional e formação continuada.

Para ponderar sobre os resultados encontrados, o presente texto se estrutura em seções, contemplando inicialmente uma reflexão sobre desenvolvimento profissional e, na sequência, descrevendo os procedimentos metodológicos e o caminho percorrido para a seleção dos dados. A partir disso, são apresentados os resultados que buscam fornecer elementos para responder ao objetivo central do estudo efetivado.

\section{Apontamentos Sobre Desenvolvimento Profissional}

De acordo com Imbernón (2011), a formação continuada é considerada um dos elementos para promover o desenvolvimento profissional do docente. Fiorentini e Crecci (2013, p.13) destacam que o termo está associado a ideia de evolução e continuidade do aperfeiçoamento dos professores. Resumidamente os autores destacam que os "professores aprendem e se desenvolvem profissionalmente mediante participação em diferentes práticas, processos e contextos, intencionais ou não, que promovem a formação ou a melhoria da prática docente". Neste sentido, os autores apontam que:

[...] há estudos nacionais e internacionais que concordam sobre a necessidade da participação plena dos professores, seja na elaboração de tarefas e práticas concernentes ao próprio desenvolvimento profissional, seja na realização de estudos e investigações que tenham como ponto de partida as demandas, problemas ou desafios, que os professores trazem de seus próprios contextos de trabalho na escola. (Fiorentini \& Crecci, 2013, p.13)

Como apontado pelos autores supracitados, o desenvolvimento profissional não deve ocorrer de forma individual, pois há necessidade de compartilhamento, troca e ajuda entre os profissionais. O termo desenvolvimento profissional também é apontado por Ponte (1998), que o considera como um movimento de "dentro para fora", a partir do qual o professor se desenvolve pessoal e também profissionalmente. Acredita-se que o professor precisa passar por um momento de interiorização e reflexão de conceitos para, assim, partir para uma mudança. Curi (2018, p.26) refere-se a alguns apontamentos de Ponte (1998) sobre desenvolvimento profissional, destacando que "além dos cursos de formação, as atividades como projetos, troca de experiências, leituras e reflexões são elementos importantes para o processo", assim o professor pode promover o seu desenvolvimento profissional quando busca ou participa de diferentes atividades que auxiliam no aprimoramento de sua prática pedagógica.

De acordo com Imbernón (1994, p.45), o desenvolvimento profissional é considerado um "processo dinâmico e evolutivo da profissão docente que inclui tanto a formação inicial quanto a permanente, englobando os processos que melhoram o conhecimento profissional, as habilidades e as atitudes". Heideman (1990, p.4), por sua vez, assinala que:

O desenvolvimento profissional dos professores vai para além de uma etapa meramente informativa; implica adaptação à mudança com o fim de modificar as atividades de ensinoaprendizagem, alterar as atitudes dos professores e melhorar os resultados escolares dos alunos. O desenvolvimento profissional de professores preocupa-se com as necessidades individuais, profissionais e organizativas.

Percebe-se que o ponto fundamental destacado por Heideman está na preocupação de melhorar os processos de ensino e de aprendizagem e, para que isso aconteça, é necessário modificar as atitudes, práticas e atividades dos professores.

Day (2001), autor que tem marcado o seu trabalho pelas investigações sobre o desenvolvimento profissional dos professores, propõe que sejam consideradas todas as experiências e as atividades, realizadas para benefício, direto ou indireto, do grupo ou da escola e que contribuem, através destes, para a qualidade da educação na sala de aula. E é nesse processo, de acordo com o autor, que os professores precisam estar abertos a mudanças, objetivando rever, renovar e ampliar seus conhecimentos e buscando, de forma individual ou coletiva, atingir melhorias nos processos de ensino e de aprendizagem do ambiente escolar no qual estão inseridos.

Para Fernandes (2010, p.90), a formação continuada é o processo de desenvolvimento que ocorre durante a vida profissional do professor, "que está articulada com sua prática pedagógica no contexto do cotidiano escolar" e é "um processo permanente, dinâmico e rico que se consolida no cotidiano pessoal e profissional dos professores e que ocorre, primordialmente, na organização do trabalho pedagógico e no espaço e no tempo da escola".

Como se pode perceber, a maioria dos autores anteriormente citados entende o desenvolvimento profissional do professor como um processo, que pode ser individual ou coletivo, mas que precisa estar relacionado com o local de trabalho e colaborar para o desenvolvimento das capacidades profissionais de cada um. Esse desenvolvimento não acontece de forma imediata e precisa ser um processo contínuo.

Curi (2018, p.26) entende como fundamental para o desenvolvimento profissional "que o professor deve ser sujeito de sua própria formação". Nessa visão, o docente aprende de forma ativa, praticando atividades de ensino, avaliação, observação e reflexão. Destaca-se que esse é um processo de longo prazo, contínuo e que permite que o professor relacione as novas experiências com os seus conhecimentos prévios. Assim, é importante considerar o ambiente escolar como ponto de partida para que as atividades de desenvolvimento 
profissional ajudam os professores a elaborar novas teorias e novas práticas pedagógicas. De acordo com os apontamentos da autora, a formação continuada é parte do processo de desenvolvimento profissional e deve considerar as necessidades do professor e a colaboração deste durante o processo de formação. A autora ainda destaca o processo colaborativo como uma metodologia eficaz, no qual o docente é levado a discutir e refletir com seus colegas.

Curi (2018) destaca alguns elementos como fundamentais para que o professor se desenvolva profissionalmente: o contexto de trabalho; seus objetivos; o professor como um sujeito que faz parte do processo, considerando seus aspectos cognitivos, afetivos e relacionais; a responsabilidade no que diz respeito às propostas e projetos voltados ao ensino e a aprendizagem. Ademais, salienta também a importância da relação que o professor consegue estabelecer com os seus colegas, dentro e fora da escola. Esses elementos precisam ser considerados no momento do planejamento de um curso de formação continuada, pois se deve levar em conta a vida desse profissional, seus projetos, suas dificuldades, seus anseios, seus conhecimentos e a relação social com o grupo.

Dessa forma, quando se pensa em promover uma formação que busca o desenvolvimento profissional do professor, deve-se ter o cuidado de não simplesmente acumular teorias e conhecimentos, mas sim, propor práticas investigativas que levem o professor a refletir sobre sua prática. Em síntese, destaca-se que a prática de reflexão precisa ser uma metodologia adotada durante a formação continuada de professores para que se promova o desenvolvimento e, principalmente, a mudança de práticas pedagógicas, pois é por meio da reflexão que o professor consegue perceber e avaliar suas ações. Assim, considera-se fundamental que esses encontros sejam promovidos no contexto escolar, considerando a realidade de sala de aula de cada professor. Ademais, aponta-se a importância da participação dos professores para compartilhar suas reflexões e conhecimentos.

\section{Procedimentos Metodológicos}

Para constituição do corpus desta pesquisa, efetivou-se um levantamento bibliográfico com o intuito de conhecer alguns estudos que abordam os temas "formação de professores" e "desenvolvimento profissional" de profissionais dos Anos Iniciais. Para tanto, realizou-se, inicialmente, um arrolamento de todas as revistas classificadas com Qualis A1 na Área de Ensino do Periódico da Capes (classificação no quadriênio
2013-2016 no Webqualis), tendo sido encontrados 145 periódicos. Na análise inicial, porém, percebeu-se que algumas se repetiam, ou eram encontradas nas versões online e impressa. Sendo assim, foram analisados 104 periódicos diferentes, dos quais 74 se aproximavam com a área que estava sendo estudada e os demais estavam voltados para a área de ensino na saúde.

Utilizou-se a metodologia de revisão sistemática, na qual são considerados estudos secundários, que têm nos estudos primários sua fonte de dados. Entende-se por estudos primários os artigos científicos que relatam os resultados de pesquisa em primeira mão e de acordo com Galvão \& Ricorte (2020, p. 58)

[...] que busca entender e dar alguma logicidade a um grande corpus documental, especialmente, verificando o que funciona e o que não funciona num dado contexto. Está focada no seu caráter de reprodutibilidade por outros pesquisadores, apresentando de forma explícita as bases de dados bibliográficos que foram consultadas, as estratégias de busca empregadas em cada base, o processo de seleção dos artigos científicos, os critérios de inclusão e exclusão dos artigos e o processo de análise de cada artigo. Explicita ainda as limitações de cada artigo analisado, bem como as limitações da própria revisão. De forma geral, a revisão de literatura sistemática possui alto nível de evidência e se constitui em um importante documento para tomada de decisão nos contextos públicos e privados.

Neste sentido, visitando os sites desses 74 periódicos selecionados, encontrou-se, no período de 2013 a 2018, um total de 23.123 títulos de artigos publicados. Após a coleta inicial, realizou-se a leitura e seleção dos títulos que se aproximavam com os temas discutidos nesta pesquisa: “formação de professores" e "desenvolvimento profissional". Ressalta-se que vários artigos foram descartados, pois os títulos já informavam que eram pesquisas desenvolvidas no ensino superior, ou estavam relacionadas à formação inicial, ou seja, não contemplavam o foco desta pesquisa. Dessa seleção resultou 370 títulos de artigos para uma posterior análise.

Realizou-se, então, a leitura dos resumos desses 370 artigos, com o intuito de identificar relações próximas com os temas em estudo, para uma posterior leitura e análise da introdução e metodologia utilizada nestes artigos. Desse modo, foram selecionados e lidos 135 artigos e após a leitura destes, foram selecionados 19 para constituíram o corpus de análise para o presente trabalho.O Quadro 1 apresenta os artigos selecionados que foram nomeados como An, sendo $\mathrm{n}=$ $1,2,3, \ldots 19$.

Continua...

Quadro 1 - Artigos selecionados

\begin{tabular}{|c|l|l|c|c|}
\hline $\mathbf{N}^{\mathbf{0}}$ & \multicolumn{1}{|c|}{ Título } & \multicolumn{1}{|c|}{ Autores } & \multicolumn{1}{c|}{ Ano } & \multicolumn{1}{|c|}{ Periódico } \\
\hline A1 & $\begin{array}{l}\text { Formação Continuada de Professores que } \\
\text { Lecionam Matemática: desenvolvendo a } \\
\text { prática reflexiva docente }\end{array}$ & $\begin{array}{l}\text { Silva, Angélica da F. G.; } \\
\text { Serrazina, Maria de L.; } \\
\text { Campos, Tânia M. M. }\end{array}$ & Bolema \\
\hline A2 & $\begin{array}{l}\text { Modelo de Competencias Profesionales de } \\
\text { Matemáticas (MCPM) y su Implementación en } \\
\text { Profesores de Enseñanza Primaria en Chile }\end{array}$ & $\begin{array}{l}\text { Díaz Q., Verónica; } \\
\text { Poblete L., Álvaro }\end{array}$ & 2016 & Bolema \\
\hline
\end{tabular}


Continuação...

\begin{tabular}{|c|c|c|c|c|}
\hline $\mathbf{N}^{\circ}$ & Título & Autores & Ano & Periódico \\
\hline A3 & $\begin{array}{l}\text { O Estudo de Aula como Processo de } \\
\text { Desenvolvimento Profissional de Professores } \\
\text { de Matemática }\end{array}$ & $\begin{array}{l}\text { Ponte, João P. da; } \\
\text { Quaresma, Marisa; } \\
\text { Mata-Pereira, Joana; } \\
\text { Baptista, Mónica }\end{array}$ & 2016 & Bolema \\
\hline A4 & $\begin{array}{l}\text { Formação continuada e suas implicações: entre } \\
\text { a lei e o trabalho docente }\end{array}$ & $\begin{array}{l}\text { Magalhães, Lígia K. C. de; } \\
\text { Azevedo, Leny C. S. S. }\end{array}$ & 2015 & Cadernos Cedes \\
\hline A5 & $\begin{array}{l}\text { Para pensar sobre a formação continuada de } \\
\text { professores é imprescindível uma teoria crítica } \\
\text { de formação humana }\end{array}$ & $\begin{array}{l}\text { Araújo, Clarissa M. de; } \\
\text { Araújo, Everson M.; } \\
\text { Silva, Rejane D. da }\end{array}$ & 2015 & Cadernos Cedes \\
\hline A6 & $\begin{array}{l}\text { Objetivos gerais de um programa de } \\
\text { desenvolvimento profissional docente }\end{array}$ & $\begin{array}{l}\text { Scarincil, Anne L.; } \\
\text { Paccal, Jesuína L. de A. }\end{array}$ & 2016 & Ciências e Educação \\
\hline A7 & $\begin{array}{l}\text { Reflexões sobre experiências de formação } \\
\text { continuada de professores em um centro de } \\
\text { ciências: trajetória, concepções e práticas } \\
\text { formativas }\end{array}$ & $\begin{array}{l}\text { Bassoli, Fernanda; } \\
\text { Lopes, José G. S.; } \\
\text { César, Eloi T. }\end{array}$ & 2017 & Ciências e Educação \\
\hline A8 & $\begin{array}{l}\text { Competências e formação de docentes dos } \\
\text { Anos Iniciais para a educação científica }\end{array}$ & $\begin{array}{l}\text { Briccia, Viviane; } \\
\text { Carvalho, Anna M. P. de }\end{array}$ & 2016 & $\begin{array}{l}\text { Ensaio: Pesquisa } \\
\text { em Educação em } \\
\text { Ciências }\end{array}$ \\
\hline A9 & $\begin{array}{l}\text { Discutindo combinatória em um processo de } \\
\text { formação continuada com professores dos anos } \\
\text { iniciais }\end{array}$ & $\begin{array}{l}\text { Assis, Adryanne M. R. B. de; } \\
\text { Pessoa, Cristiane A. dos S. }\end{array}$ & 2015 & $\begin{array}{l}\text { Revista Brasileira e } \\
\text { Estudos Pedagógicos }\end{array}$ \\
\hline A10 & $\begin{array}{l}\text { Formação continuada de professores em } \\
\text { Matemática visando ao desenvolvimento para } \\
\text { o exercício pleno da cidadania: um recorte da } \\
\text { Trajetória }\end{array}$ & $\begin{array}{l}\text { Groenwald, Claudia L. O.; } \\
\text { Justo, Jutta C. R.; } \\
\text { Gelle, Marlise }\end{array}$ & 2013 & $\begin{array}{l}\text { Revista Brasileira e } \\
\text { Estudos Pedagógicos }\end{array}$ \\
\hline A11 & $\begin{array}{l}\text { Estrategias para la mejora de la práctica } \\
\text { docente. Uma investigacion-acción } \\
\text { colaborativa para el uso inovador de Las TIC }\end{array}$ & $\begin{array}{l}\text { Fernandez-Diaz, Elia; } \\
\text { Salvador, Adelina C. }\end{array}$ & 2013 & $\begin{array}{l}\text { Revista electrónica } \\
\text { interuniversitaria } \\
\text { de formación del } \\
\text { professorado }\end{array}$ \\
\hline A12 & $\begin{array}{l}\text { The influence of an in-service programme on } \\
\text { primary teachers conceptions about practical } \\
\text { work }\end{array}$ & $\begin{array}{l}\text { Correia, Marisa; } \\
\text { Freire, Ana M. }\end{array}$ & 2016 & $\begin{array}{l}\text { Revista electrónica } \\
\text { interuniversitaria } \\
\text { de formación del } \\
\text { professorado }\end{array}$ \\
\hline A13 & $\begin{array}{l}\text { Professional development of mathematics } \\
\text { Teachers implementing probabilistic } \\
\text { simulations In elementary school classrooms }\end{array}$ & $\begin{array}{l}\text { Souza, Leandro de O.; } \\
\text { Lopes, Celi E.; } \\
\text { Mendonça, Luzinete de O. }\end{array}$ & 2014 & $\begin{array}{l}\text { Statistics education } \\
\text { research jornal }\end{array}$ \\
\hline A14 & $\begin{array}{l}\text { Collaborative professional development for } \\
\text { Statistics teaching: a case study of two Middle- } \\
\text { school mathematics teachers }\end{array}$ & $\begin{array}{l}\text { Souza, Leandro de O.; } \\
\text { Lopes, Celi E.; } \\
\text { Pfannkuch, Maxine }\end{array}$ & 2015 & $\begin{array}{l}\text { Statistics education } \\
\text { research jornal }\end{array}$ \\
\hline A15 & $\begin{array}{l}\text { Using an Exploratory Professional } \\
\text { Development Initiative to Introduce iPads in } \\
\text { the Early Childhood Education Classroom }\end{array}$ & $\begin{array}{l}\text { Vaughan, Michelle; } \\
\text { Beers, Courtney }\end{array}$ & 2017 & $\begin{array}{l}\text { Early Childhood } \\
\text { Education Journal }\end{array}$ \\
\hline A16 & $\begin{array}{l}\text { Technologies and reformed-based science } \\
\text { instruction: The examination of a professional } \\
\text { development model focused on upporting } \\
\text { science teaching and learning with } \\
\text { technologies. }\end{array}$ & $\begin{array}{l}\text { Campbell, Todd; } \\
\text { Longhurst, Max L.; } \\
\text { Wang, Shiangkwei; } \\
\text { Coster, Daniel. }\end{array}$ & 2015 & $\begin{array}{l}\text { Journal of Science } \\
\text { Education and } \\
\text { Technology }\end{array}$ \\
\hline A17 & $\begin{array}{l}\text { The Impact of a Professional Development } \\
\text { Programme on Primary Teachers' Classroom } \\
\text { Practice and Pupils' Attitudes to Science }\end{array}$ & Smith, Greg & 2015 & $\begin{array}{l}\text { Research in Science } \\
\text { Education }\end{array}$ \\
\hline A18 & $\begin{array}{l}\text { Mathematics professional development as } \\
\text { design for boundary encounters }\end{array}$ & $\begin{array}{l}\text { Sztain, Paola; } \\
\text { Wilson, P. Holt; } \\
\text { Edgington, Cyndi; } \\
\text { Myers, Marrielle; }\end{array}$ & 2014 & $\begin{array}{l}\text { ZDM Mathematics } \\
\text { Education }\end{array}$ \\
\hline A19 & $\begin{array}{l}\text { Impact of professional development involving } \\
\text { modelling on teachers and their teaching }\end{array}$ & $\begin{array}{l}\text { Maass, Katja Maass; } \\
\text { Engeln, Katrin }\end{array}$ & 2018 & $\begin{array}{l}\text { ZDM Mathematics } \\
\text { Education }\end{array}$ \\
\hline
\end{tabular}

Fonte: Dados da pesquisa. 
Dando continuidade aos estudos, buscou-se aprofundar as leituras dos 19 artigos para identificar os principais objetivos, o referencial teórico utilizado, a metodologia de pesquisa e os resultados em cada um dos artigos.

\section{Dados Obtidos e Análise}

Após a leitura e análise dos 19 artigos selecionados, com foco em desenvolvimento profissional, percebeu-se várias possibilidades de atingir os objetivos principais de cada pesquisa, destacando que o desenvolvimento profissional é atingido a partir de um conjunto de fatores, práticas e atividades. Assim, os autores dos artigos A1, A2, A8, A9, A10, A11, A13, A14 e A19 buscaram o desenvolvimento profissional, oferecendo cursos de formação continuada com diferentes focos - alguns na área de matemática (A1, A2, A9, A10, A13, A14 e A19) e outros na área de ciências (A8 e A17), envolvendo recursos tecnológicos (A11 e A16) ou atividades experimentais (A8). A duração desses encontros de formação varia de um encontro semanal durante um período de um ano, a outros com um período maior de formação, pois fazem parte de um grupo de pesquisa, que são o caso dos relatos dos artigos (A16, A17 e A18), que desenvolveram as pesquisas num período de dois a três anos.

Esses trabalhos apresentam como principais objetivos: "analisar diferentes fatores que podem interferir no desenvolvimento profissional de professores, [...] quando estes estão inseridos em um processo de formação em serviço" (A $1^{2}$, p. 1506); "desenvolver e implementar uma prática pedagógica que associa o conhecimento matemático e a prática em sala de aula de professores que ensinam matemática" (A2, p. 786); analisar um curso de formação continuada, o desenvolvimento da prática e as reflexões de um grupo de professoras, com a intenção de observar quais fatores foram fundamentais para a inserção dessas docentes na Educação Científica (A8); analisar o efeito de uma formação continuada que aborda um conteúdo específico (A9, A10, A13 e A14).

Observou-se que as propostas de formação citadas nos artigos foram diferenciadas, sendo que no A1 e no A9 os autores realizaram uma entrevista inicial para conhecer os participantes, sua trajetória profissional e sua formação inicial. No entanto, todas as propostas buscaram realizar momentos de reflexão sobre a prática. Cabe ressaltar também que os autores dos artigos A1, A2, A8, A9, A10, A13 e A14 fazem referência à importância do acompanhamento da aplicação das práticas em cotidiano escolar, destacando em alguns momentos a importância da formação em contexto escolar como forma de auxiliar no processo de desenvolvimento profissional do professor.

Os artigos classificados no grupo desenvolvimento profissional apresentam como principais resultados alcançados, o aumento de confiança e segurança dos professores para o desenvolvimento de prática diferenciada; a reflexão sobre o processo de ensino e aprendizagem; o desconforto dos professores quando eram realizadas observações das práticas pedagógicas; e indícios de mudanças de atitude em relação à prática destes profissionais. E, como ainda apontado pelos autores do artigo A1, percebeu-se "o crescimento da disposição manifestada pelos professores de estudar de forma coletiva - o que pode ter uma relação com a troca de experiências observadas durante o processo formativo" (A1, p. 1521).

A pesquisa A3 destaca a melhoria de algumas habilidades, como a "capacidade de usar diferentes estratégias de ensino", e "um aumento significativo na capacidade de aplicar o conhecimento, relacionado ao ensino do conhecimento pedagógico e do saber-fazer do ensino e da aprendizagem" (p. $2)^{3}$. Além disso, os autores perceberam avanços na capacidade de trabalhar de forma colaborativa, o que possibilitou ao grupo realizar momentos de reflexão em conjunto, discutir, identificar problemas, experimentar práticas diferenciadas e avaliá-las (A2).

No estudo apresentado no artigo A8, os autores apontam que é necessário desenvolver momentos de formação que busquem aprimorar o conhecimento de áreas específicas do processo de ensino. Os autores destacam que "a didática das ciências possui conhecimentos tanto metodológicos como conceituais que são característicos, únicos e que se demonstraram essenciais para a inserção dos professores nesse universo" (p. 17). Assim, os autores defendem que a formação de professores de áreas específicas precisa abordar as competências de organizar e planejar propostas pedagógicas específicas de cada área:

formação deve estar diretamente relacionada com a prática. Passar pela situação de ensino como aprendiz, observando sua própria prática, refletir sobre como atividades serão aplicadas em sala de aula (qual a postura do professor, quais questões devem ser colocadas, qual é o tempo necessário para que os alunos reflitam sobre ela) são passos fundamentais para que o professor ou professora possam desenvolver sua segurança no trabalho com a disciplina e, consequentemente, no momento de condução do processo de ensino-aprendizagem (A8, p. 17).

No artigo A9, os autores destacam que "após os momentos de formação, a docente passou a refletir mais claramente" (A9, p. 679) sobre os processos de ensino e de aprendizagem. No artigo A10, os autores enfatizam que a formação continuada realizada no ambiente escolar precisa proporcionar momentos que desafiem os professores a se desenvolverem como profissionais, de forma colaborativa: "Os professores precisam aprender a aprender para aprender a ensinar. Acredita-se que a qualificação da prática docente favorece que a escola se torne

2 Como o material deste estudo empírico são os 38 artigos, quando foi usado um excerto desses artigos a denominação será apenas o número do artigo de acordo com o quadro 1 e a respectiva página.

3 Tradução das autoras 
um espaço de promoção da igualdade de condições entre os seres humanos" (A10, p. 835).

$\mathrm{O}$ artigo A14 apresenta parte de uma pesquisa maior que descreve alguns ciclos para proporcionar o desenvolvimento profissional. Os autores ressaltam que esse modelo pode ter o potencial de fornecer aos professores os conceitos e conteúdos necessários para começar a desenvolver seus conhecimentos e para enfrentar os desafios na educação, pois "podem ajudar a promover o debate e reflexões sobre as ações necessárias para implementar abordagens de ensino e aprendizagem" ( $p$. 128). Destacam que "o planejamento colaborativo de aulas também abordou a necessidade de os professores aprenderem a projetar sua própria aula" (p. 129), e que "a criação de um ambiente colaborativo é fundamental para facilitar a mudança na prática docente" (A14, p. 129).

Os artigos A4, A5, A6 e A7 são estudos bibliográficos realizados a partir de documentos de formação e de análises de programas de formação, com objetivo de discutir questões relativas à formação continuada de professores (A4), apontar qual as contribuições da teoria crítica da formação humana para os processos de formação (A5), "analisar um programa de desenvolvimento profissional docente sob o enfoque da atuação do formador", buscando investigar como este desenvolveu "a reflexão sobre a prática, o desenvolvimento da autonomia e a compreensão de uma concepção de ensino" (A6 p. 1063), e analisar as propostas de formação de professores realizadas em centros e museus de ciências (A7).

Os principais resultados destacados no A4 foram as influências de metodologias internacionais nos processos de formação. Os autores salientam a necessidade de "renovações institucionais, metodológicas, teóricas, ético-morais e mecanismos de divulgação do conhecimento" (p. 32). Os pesquisadores defendem que a formação continuada é

parte do processo de formação ao longo da carreira, na medida em que acompanhar pesquisas, produções teóricas do campo, realizar novos cursos, inovar práticas pedagógicas, a partir do contexto em que atuam os professores, constituem procedimentos que complementam a formação inicial. Esta deveria estar presente em todas as propostas de formação, buscando suprir distanciamentos teórico/práticos/metodológicos, advindos da produção de novos conhecimentos nas mais diversas áreas, em resposta às demandas econômica, social, tecnológica e cultural da humanidade" (A4, p. 32).

A pesquisa desenvolvida pelos autores do A5 defende a importância da formação continuada de professores voltada para uma formação humana. Assim, o professor se forma, analisando criticamente seu processo de formação como ser humano. Os autores acreditam que é fundamental "assumir de forma reflexiva uma filosofia da educação que guie as nossas práticas de formação continuada de professores" (A5, p. 69).

O estudo apresentado em A6 relaciona as necessidades dos professores com "o desenvolvimento da capacidade reflexiva e de investigação da prática, a compreensão de uma concepção de ensino e a promoção da autonomia profissional" (p. 1065). Os autores constataram que, com a proposta inicial do formador em cada encontro, que solicitava aos professores que relatassem suas aulas, era proporcionada atitude reflexiva "com foco nos alunos e nas interações entre eles e com o professor, e entre eles e o conteúdo" (A6, p. 1069).

Já no artigo A7, a partir das análises dos momentos de formação continuada vivenciada pelos professores, é possível encontrar indícios que apontam mudanças na concepção destes docentes. Os autores destacam "a importância de pesquisas que busquem avaliar a articulação teórico-prática dos programas de formação continuada de professores, priorizando as demandas dos docentes em sintonia com os resultados das pesquisas educacionais" (A7, p. 831). Nos resultados apontados pelas autoras do artigo A19, destaca-se a importância do interesse dos professores pelo assunto da formação, pela participação dos momentos de estudo para atingir os resultados.

Os autores dos artigos A16 e A18, destacam a importância de um processo de desenvolvimento profissional realizado durante um período maior de tempo. No artigo A18 se encontra uma revisão bibliográfica que apresenta algumas características importantes para atingir o desenvolvimento profissional dos professores. Assim, destacam as competências e práticas dos professores, suas necessidades, discussão dos desafios que enfrentam, estímulo a cooperação entre os docentes, modos de apoiar os professores nas diferentes etapas do trabalho, incentivo a análise de casos de aulas e que os cursos devem usar vários formatos instrucionais, como trabalho em grupo e compartilhamento de ideias, além de fomentar a reflexão sobre suas crenças em relação ao ensino de matemática e ciências e suas experiências de ensino.

Para finalizar a análise dos artigos da categoria de desenvolvimento profissional, apresenta-se o artigo A12, que teve como objetivo investigar como um programa em serviço influenciou nas concepções sobre trabalho prático dos professores dos anos iniciais. Nesse artigo, foi desenvolvido um guia para os professores, com ideias para realizar trabalhos práticos com alunos, com explicações científicas sobre cada conteúdo e atividades de avaliação. Os autores comentaram que a professora que apresentou mudança mais significativa em relação à proposta do programa foi aquela que promoveu atividades práticas com mais frequência e que continuava utilizando-as em sala de aula. Nesse sentido, constataram que os professores precisam querer fazer parte do processo de formação.

Os autores do A12 destacam que os professores concordaram que era possível realizar atividades práticas utilizando materiais simples, mas mesmo após as escolas parceiras do programa de pesquisa terem recebido materiais, a maioria dos participantes continuou apontando a falta de recursos como uma das dificuldades. Este estudo ressalta que um curso de formação que busca o desenvolvimento profissional com duração de 63 horas pode não ser suficiente para atingir os objetivos propostos, porém aponta que o 
trabalho colaborativo dos professores teve um resultado positivo nas concepções e práticas dos professores. Ademais, comentam que:

a participação coletiva de professores da mesma escola em iniciativas de desenvolvimento profissional permite que os professores desenvolvam objetivos comuns, compartilhem materiais de ensino e troquem ideias e experiências decorrentes de um contexto comum, reduzindo sua relutância em adotar o ensino baseado em investigação centrado no aluno (A12, p. 268) $)^{4}$.

Percebe-se que os artigos analisados apresentam momentos de formação mais amplos para atingir o desenvolvimento profissional dos professores. Concluindo a análise desta coletânea de artigos que foram selecionados a partir de critérios pré-estabelecidos, pode-se perceber muitas características semelhante entre elas, como: a importância da participação do grupo de professores, a troca e compartilhamento de ideias e atividades, além de alguns apontamentos como em relação a durante dos momentos de formação que podem ser importantes para a constituição de uma formação continuada que busca o desenvolvimento dos professores participantes.

\section{Considerações Finais}

Em relação aos objetivos desta pesquisa destaca-se que as metodologias de formação continuada que mais foram citadas nos estudos analisados, estão relacionadas com o envolvimento dos professores, a participação no planejamento, a troca de atividades, ideias entre os participantes e também com o pesquisador. Os estudos apontam também o período de formação, que precisa ser por um tempo mais longo, onde seja possível o acompanhamento do docente durante a aplicação de práticas pedagógicas.

Em relação aos principais enfoques metodológicos adotados nessas investigações, estes estão relacionados à importância da troca e compartilhamento de atividades que auxiliam no processo pedagógico. Também destacam a formação em serviço como uns dos aspectos positivos para melhoria da prática docente.

Por meio da análise dos 19 artigos selecionados com o tema desenvolvimento profissional, percebeu-se a importância de momentos de formação com um período maior de duração para atingir os objetivos propostos com um determinado grupo. Ademais, os resultados positivos obtidos com as formações realizadas em contexto escolar auxiliaram no processo de desenvolvimento profissional do professor. $\mathrm{O}$ aumento de confiança e segurança dos professores para o desenvolvimento de prática diferenciada; a reflexão sobre o processo de ensino e aprendizagem; o desconforto dos professores quando eram realizadas observações das práticas pedagógicas; indícios de mudanças de atitude em relação à prática destes profissionais, são apontamentos destacados pelos autores nestas pesquisas.
Por meio deste estudo, percebeu-se que para ocorrer o desenvolvimento profissional, são necessárias renovações institucionais, metodológicas, teóricas e práticas. Destaca-se que a formação continuada é parte do processo de formação ao longo da carreira, na medida em que acompanhar pesquisas, realizar novos cursos, inovar com práticas pedagógicas, no contexto em que atuam os professores, constitui-se em procedimentos que complementam a sua formação inicial. Este tipo de formação continuada deveria estar presente quer em cursos formais quer em informais, suprindo distanciamentos teórico/práticos/metodológicos.

Após a análise destes artigos pode-se inferir sobre dois pontos fundamentais para a formação: o compartilhamento de conhecimento e o trabalho continuado. Nesta perspectiva, é possível acreditar, desejar, sonhar e defender a formação continuada de professores dentro de uma perspectiva da formação compartilhada. Desse modo, o professor forma a si próprio e aos colegas por meio de planejamento, compartilhamento e troca de conhecimento.

\section{Referências}

Araújo, C. M. de; \& Araújo, E. M.; \& Silva, R. D. da. (2015). Para pensar sobre a formação continuada de professores é imprescindível uma teoria crítica de formação humana. Revista Cadernos Cedes, 35(95) 57-73.

Assis, A. M. R. B. de; \& Pessoa, C. A. dos S. (2015). Discutindo combinatória em um processo de formação continuada com professores dos anos iniciais. Revista Brasileira e Estudos Pedagógicos, 96(244) 666-682.

Bassoli, F.; \& Lopes, J. G. S.; \& César, E. T. (2017). Reflexões sobre experiências de formação continuada de professores em um centro de ciências: trajetória, concepções e práticas formativas. Revista Ciências e Educação, 23(4), 817-834.

Briccia, V.; \& Carvalho, A. M. P. de. (2016). Competências e formação de docentes dos anos iniciais para a educação científica. Revista Ensaio: Pesquisa em Educação em Ciências. Belo Horizeonte.

Campbell, T.; \& Longhurst, M. L.; \& Wang, S.; \& Coster, D. (2015). Technologies and Reformed-Based Science Instruction: The Examination of a Professional Development Model Focused on Supporting Science Teaching and Learning with Technologie. Journal of Science Education and Technology.

Correia, M.; \& Freire, A. M. (2016). The influence of an in-service programme on primary teachers conceptions about practical work. Revista Electrónica Interuniversitaria de Formación del Professorado, 19(2), 259-272.

Curi, E. (2018). Reflexões sobre um projeto de pesquisa que envolve grupos colaborativos e a metodologia lesson study. In.: E., Curi, J.C. Nascimento, J.P. Vece, Grupos colaborativos e lesson study: contribuições para a melhoria do ensino de matemática e desenvolvimento profissional de professores. São Paulo: Alexa Cultural.

Day, C. (2001). Desenvolvimento profissional dos professores - os desafios da aprendizagem permanente. Porto: Porto Editora. 
Díaz Q., V.; \& Poblete L., Á. (2016). Modelo de Competencias Profesionales de Matemáticas (MCPM) y su Implementación en Profesores de Enseñanza Primaria en Chile. Revista Bolema, 30(55), 786-807.

Fernandes, R.C.A. (2010). Educação Continuada de professores no espaço-tempo da coordenação pedagógica: avanços e tensões. In.: I.P.A. Veiga, A escola mudou. Que mude a formação de professores!. Papirus.

Fernández Díaz, E.; \& Calvo Salvador, A. (2013). Estrategias para la mejora de la práctica docente. Una investigacion acción colaborativa para el uso innovador de las TIC Revista Electrónica Interuniversitaria de Formación del Profesorado, 16(2), 121-133

Fiorentini, D.; \& Crecci, V. (2013). Desenvolvimento Profissional DOCENTE: Um Termo Guarda-Chuva ou um novo sentido à formação? Revista Brasileira de Pesquisa sobre Formação Docente, 5(8), 11-23.

Galvão, M.C.B., Ricarte, I.L.M. (2020). Revisão sistemática da literatura: conceituação, produção e publicação. LOGEION: Filosofia da informação, 6(1), 57-73.

Groenwald, C. L. O.; \& Justo, J. C. R.; \& Gelle, M. (2013). Formação continuada de professores em Matemática visando ao desenvolvimento para o exercício pleno da cidadania: um recorte da Trajetória. Revista Brasileira e Estudos Pedagógicos, 94(238),811-838.

Heideman, C. (1990). Introduction to staff develop- ment. In P. Burke. Programming for staff development (pp.3-9). London: Falmer Press.

Imbernón, F. (1994). La Formación del Profesorado. Barcelona, Espanha: Paidós.

Imbernón, F. (2011). Formação Docente e Profissional: formar-se para a mudança e a incerteza. São Paulo: Cortez.

Maass, K. M.; \& Engeln, K. (2018). Impact of professional development involving modelling on teachers and their teaching. ZDM Mathematics Education.

Magalhães, L.K.C., Azevedo, L.C. S.S. (2015). Formação continuada e suas implicações: entre a lei e o trabalho docente. Revista Cadernos Cedes, 35(95), 15-36.

Ponte, J.P., Quaresma, M., Mata-Pereira, J., Baptista, M. (2016). $\mathrm{O}$ estudo de aula como processo de desenvolvimento profissional de professores de matemática. Revista Bolema, 30(56), 868-891.

Ponte, J.P. (1998). Didácticas Específicas e Construção do Conhecimento Profissional. In. Investigar e formar em educação. Actas do IV Congresso da SPCE. Porto: Sociedade Portuguesa de Ciências da Educação.

Scarincil, A.L., Pacca, J. L.A. (2016). Objetivos gerais de um programa de desenvolvimento profissional docente. Revista Ciências e Educação, 22(4), 1063-1084.

Silva, A.F. G., Serrazina, M.L., Campos, T.M.M. (2014). Formação continuada de professores que lecionam matemática: desenvolvendo a prática reflexiva docente. Revista Bolema, 28(50), 1505-1524.

Smith, G. (2015). The Impact of a Professional Development Programme on Primary Teachers' Classroom Practice and Pupils' Attitudes to Science. Research in Science Education.

Souza, L.O., Lopes, C.E., Pfannkuch, M. (2015). Collaborative professional development for Statistics teaching: a case study of two Middle-school mathematics teachers. Revista Statistics Education Research Jornal, 14(1), 112-134.

Souza, L.O., Lopes, C.E., Mendonça, L.O. (2014). Professional development of mathematics Teachers implementing probabilistic simulations In elementary school classrooms. Revista Statistics education research jornal. Statistics Education Research Journal, 13(2), 83-92.

Sztain, P., Wilson, P. H.,Edgington, C., Myers, M. (2014). Mathematics professional development as design for boundary encounters. ZDM Mathematics Education.

Vaughan, M., \& Beers, C. (2017). Using an Exploratory Professional Development Initiative to Introduce iPads in the Early Childhood Education Classroom. Early Childhood Educ J 45, 321-331 doi: https://doi.org/10.1007/s10643-0160772-3. 